\title{
Quantitative description of the morphology of polyurethane nanocomposites for medical applications
}

\author{
J. Ryszkowska \& B. Waśniewski \\ Warsaw University of Technology, \\ Faculty of Materials Science and Engineering, Poland
}

\begin{abstract}
This paper presents the application of stereology methods to the description of morphological properties of polyurethane nanocomposites for medical applications. The study of the cross-section surface structure of the obtained materials was performed by Atomic Force Microscopy. The volume of hard phase agglomerate was used to evaluate the degree of phase separation of the examined nanocomposites. The relationships between the domain agglomerate characteristics and the properties of nanocomposites obtained from them were analysed.

The results showed that nanocomposites with non-modified nanosilica dioxide $\left(\mathrm{SiO}_{2}\right)$ and nanosilica dioxide modified with $\mathrm{NH}_{2}$ groups differs from polyurethane within the following properties: size and volume of the agglomerates of the hard domains, biocompatibility, thermo-mechanical and abrasive wear resistance.
\end{abstract}

Keywords: nanocomposites, polyurethane, structure, image analysis, biomedical application

\section{Introduction}

Polyurethanes (PURs) and their nanocomposites are a versatile plastic material, formulated to provide good biocompatibility, flexural endurance, high strength, high abrasion resistance and processing versatility over a wide range of applications [1]. The most common use in medical devices is in short-term implants [2]. Polyurethane elastomers are linear segmented copolymers 
consisting of a relatively flexible component derived from a macrodiol called soft segment, and a relatively hard and stiff component derived from a diisocyanate and a chain extender called hard segment (Fig 1). Thermodynamic incompatibility of these segments leads to microphase separation. The domain structure formed by microscopic phase separation presents similar elastomeric properties to those shown for cross-linked rubber networks. The mechanical strength of this structure can be attributed to hard microdomains physically cross-linked through hydrogen bonding and dispersion forces, acting as fillerlike reinforcement for the soft segment [3]. Polyurethanes are characterized by a complex morphology which is dependent upon the precise nature of the hard and soft segments and their composition, use of nanoparticles, preparation method and its parameters. All these factors influence the morphological factors such as degree of microphase separation, crystallinity, the domain agglomerate characteristics, and define properties such as hardness, stiffness, tensile strength, clarity and biocompatibility [1-7].

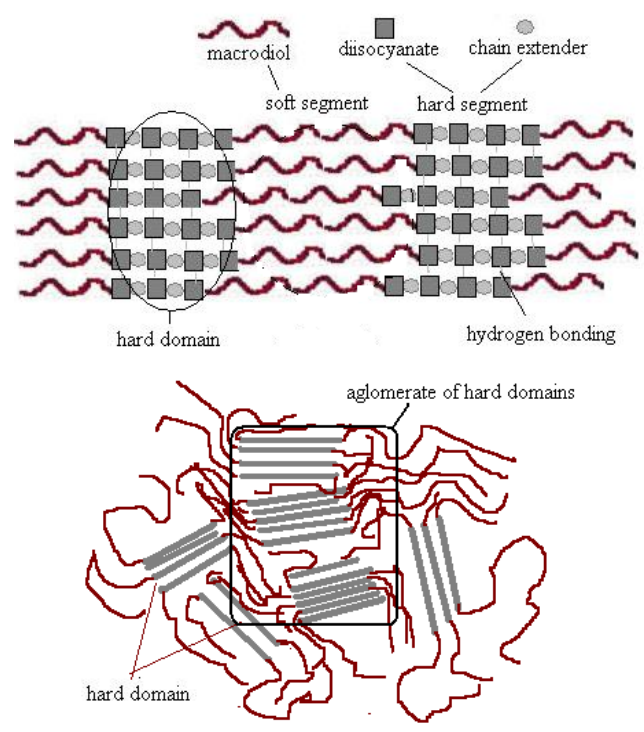

Figure 1: Domains structure of polyurethane.

This paper presents the application of stereology methods to the description of morphological properties of polyurethane nanocomposites for medical application. Stereological parameters [8-10] chosen for analysis were used to evaluate the degree of phase separation of the examined nanocomposites. Relationships between the domain agglomerate characteristics and the properties of the nanocomposites obtained from them were analysed. 


\section{Experimental}

\subsection{Materials}

The following reactants were used in the synthesis of PURs: polyoxythetramethylene glycol (PTMG) of molecular weight $2023 \mathrm{~g} / \mathrm{mol}$ (Therathane ${ }^{\circledR}$ 2000) was supplied by Du Pont Nemours Co.; 4.4'diphenylmethane diisocyanate (MDI) purchased from Aldrich Chemical Co. (Germany); ethylene glycol (GE) and glycerine (G) POCH (Gliwice, Poland). Polyol was dehydrated by mixing under vacuum for $2 \mathrm{~h}$ at $120^{\circ} \mathrm{C}$. Ethylene glycol and glycerin was dried under a molecular sieve.

Nanosilica powder and nanosilica powder modified with NH2 groups, with primary particle size of $75 \mathrm{~nm}$ were used as nanofiller (ICHP Warsaw). To prepare the composites, nanosilica - polyetherodiols $20 \% \mathrm{wt}$. concentrate was made. Firstly, polyetherodiol was melted down in the oven under $80^{\circ} \mathrm{C}$ degree. Then nanosilica was put into it and mixed with ultrasonic homogenizer VCX 750 by Sonics during $30 \mathrm{~min}$ in pulse mode $3 / 3$ (3sec mixing, $3 \mathrm{sec}$ stop).

\subsection{Polyurethane and nanocomposites synthesis}

Segmented polyether based polyurethanes with substrates molar ratio PTMG: MDI: GE: G equal to 40:80:27:24 (1:2:0.679:0.151), constant isocyanates index of 1.05 and with hard segment contents $20 \mathrm{wt} . \%$ was synthesized using a onestep polymerisation method. The polyol was cooled to $70^{\circ} \mathrm{C} \pm 3^{\circ} \mathrm{C}$, with glycol added and glycerin blended for $5 \mathrm{~min}$. Then the mixture was cooled to $60^{\circ} \mathrm{C} \pm 3^{\circ} \mathrm{C}$ and MDI added. The samples were obtained with free casting method. The heat up process was carried out in the oven for 16 hours. To prepare the composites, appropriate quantities of concentrate were added to the polyol. The mixture was dehydrated in temperature of $120^{\circ} \mathrm{C} \pm 5^{\circ} \mathrm{C}$ under $2-5 \mathrm{hPa}$ pressure. Next the process was run in the same way as polyurethane synthesis. Description of achieved materials is presented in Table 1 .

Table 1: Description of the achieved materials.

\begin{tabular}{|l|c|c|c|c|c|c|c|}
\hline Sample & 0 & 1 & 2 & 3 & $1 \mathrm{~A}$ & $2 \mathrm{~A}$ & $3 \mathrm{~A}$ \\
\hline Amount of nanofiller [wt.\%] & 0 & 0.5 & 1.0 & 2.0 & 0.5 & 1.0 & 2.0 \\
\hline Modification of nanofiller & - & - & - & - & $-\mathrm{NH}_{2}$ & $-\mathrm{NH}_{2}$ & $-\mathrm{NH}_{2}$ \\
\hline
\end{tabular}

\subsection{Characterization}

\subsubsection{Dynamic mechanical analysis}

Dynamic tests, by dynamic mechanical analysis (DMA) on a Thermal Instruments dynamic mechanical analyzer (Q800 TA), were also carried out in three-point bending mode on specimens with dimensions of $12 \times 2 \times 60 \mathrm{~mm}^{3}$. Tests were performed with the amplitude of deformation during the bending of $25 \mu \mathrm{m}$. The frequency-dependent storage modulus was also evaluated with a 
4.5-9 $\mathrm{Hz}$ frequency sweep at a constant temperature of $37^{\circ} \mathrm{C}$ with $1.5 \%$ strain and $0.01 \mathrm{~N}$ static force. Similar parameters were used by Hafeman and coworkers [11]. The storage modulus ( $\left.E^{\prime}\right)$ value was recorded as a function of frequency.

\subsubsection{Abrasion resistance}

The abrasion resistance of test samples was measured with a SchopperSchlobach instrument with an APGi circulating roller from Heckert, and the procedure complied with the standard PN-ISO [12]. The test pieces are in the form of a roll (16 \pm 0.2 in diameter and $2 \mathrm{~mm}$ high). Standard rubber from (The Institute for Engineering of Polymer Materials and Dyes, Elastomer and Rubber Technology Division in Piastów) was used as reference material [13]. The abrasion resistance index $(\Delta \mathrm{V})$ was calculated with the following relation:

$$
\Delta V=\frac{V s}{V t}, 100 \%
$$

where $V S$ is the loss of volume of the standard rubber $\left(\mathrm{mm}^{3}\right)$ and $V t$ is the loss of volume of the test sample $\left(\mathrm{mm}^{3}\right)$.

The density figures for the test pieces, which were necessary for calculations, were found by the method described in the standard PN-ISO [14].

\subsubsection{Atomic Force Microscopy (AFM)}

AFM images were recorded at $37^{\circ} \mathrm{C}$ in air using a Digital Instrument Multimode Nanoscope V (Digital Instruments, Santa Barbara, CA) operating in the tapping regime mode using antimony doped silicon cantilever tips (POL-15, 130 do $250 \mathrm{kHz}, 48 \mathrm{~N} / \mathrm{m}$ ). Scanner was used with scan rates between 0.5 and $1 \mathrm{~Hz}$. All images are subjected to a first-order plane-fitting procedure to compensate for sample tilt. The microstructure of polyurethane was investigated on micro sections. These were prepared using a rotary microtom RM 2165 (Leica) with a LN 21 cooling device working at $-60^{\circ} \mathrm{C}$.

\subsubsection{Image analysis}

Binary images revealing hard domains agglomerates were produced via digital processing of AFM images. The size and volume fractions of the hard domains agglomerates in polyurethane and nanocomposites were determined by measurements on their sections [15]. Linear covariance method was used for the description of the distribution of particles. The image was transferred to MicroMeter software and quantitative analysis was performed. The diameters were randomly determined on 5 microphotographs.

\subsubsection{Fourier transform infrared (FTIR) spectroscopy}

Infrared spectra of PURs were collected using a FTIR spectrophotometer (Thermo Electron Corporation model Nicolet 6700). Measurements were carried out using attenuated total reflectance (ATR) technique. Each sample was scanned 64 times at a resolution of $4 \mathrm{~cm}-1$ over the frequency range of 4000-400 $\mathrm{cm}^{-1}$. Analysis of FTIR data enabled to determine the carbonyl hydrogenbonding index (R). A straight baseline was drawn in the spectrum between 1780 
$\mathrm{cm}^{-1}$ and $1640 \mathrm{~cm}^{-1}$ and the carbonyl stretching zone was corrected by subtracting the baseline. To estimate the signal strengths, peak modeling of the infrared active carbonyl bands was carried out using the Gaussian curve-fitting method software OMNIC 7.3. The carbonyl absorption bands were deconvoluted into component bands, the peak area of these bands was measured and carbonyl hydrogen-bonding index R was calculated using Eq. (1) $[16,17]$ :

$$
R=\frac{A_{\text {bonded }}}{A_{\text {free }}}
$$

Moreover, the degree of phase separation (DPS) was obtained through Eq. (2):

$$
D P S=\frac{R}{R+1}
$$

\section{Results and discussion}

In polyurethanes application as short-term implants the modulus of elasticity and surface properties must very often be changed. The one way to solve the problem is the use of nanofiller [18-20]. Nanocomposites exhibit advantageous mechanical and physical properties already at small addition of modifying particles, frequently lower than $5 \mathrm{wt} \%$. Most of nanofillers occur without any surface modification. However, sometimes we need to modify nanoparticles to obtain better dispersion of nanofiller in polymer matrix, for instance. One of the modifications is a chemical one relying on attaching functional groups i.e. $\mathrm{COOH},-\mathrm{NH}_{2},-\mathrm{NCO},-\mathrm{OH}$ to nanofiller [20-24].

In this study were used polyetherourethanes with $0,5-2 \mathrm{wt} \%$ of nanosilica and nanosilica modified with amino groups.

The change in elasticity module was examined in the course of three-point bending as well as abrasion wear of fabricated materials (Table 2). Nanofiller introduction change the storage modulus and abrasion wear of polyurethane matrix.

Table 2: Results of dynamic three point bending and abrasion wear of the PU and $\mathrm{PU} / \mathrm{SiO}_{2}$ composites.

\begin{tabular}{|l|c|c|c|c|c|c|c|}
\hline Sample & 0 & 1 & 2 & 3 & $1 \mathrm{~A}$ & $2 \mathrm{~A}$ & $3 \mathrm{~A}$ \\
\hline $\begin{array}{l}\text { E', storage modulus by frequency } 5 \mathrm{~Hz} \text { at } \\
37^{\circ} \mathrm{C}, \mathrm{MPa}\end{array}$ & 24.6 & 2.8 & 32.6 & 30.8 & 3.4 & 40.6 & 41.6 \\
\hline$\Delta \mathrm{V}$, abrasion wear, $\mathrm{dm}^{3}$ & 35.2 & 26.0 & 27.7 & 48.2 & 23.0 & 27.3 & 31.8 \\
\hline
\end{tabular}

The introduction of $0.5 \mathrm{wt} \%$ of nanofiller brings about a decrease in storage modulus and abrasion wear; bigger amounts of the filler make the two values grow. The use of modified nanofiller results in the fact that the obtained nanocomposites have a higher storage modulus at lower abrasion wear.

In order to explain the mechanism of the influence of nanofiller on polyurethane matrix structure microscopic observations were carried out of the cross-section surface of fabricated materials using AFM. An AFM tapping mode 
is used to depict topographic features and the spatial variation in surface by height and phase imaging. For the examined materials the appearances of topographic and phase images are similar and show less obviously surface morphology related to hard domain and soft domain separation. An exemplary phase image of surface cross-section of examined PU is shown in Fig. 2a. Binary images of all face images of the polyurethanes and nanocomposites were performed and those selected from them were shown in Fig. 2 (b-f). The neat PU cut surface showed microphase separation in phase images, the hard phase of the polyurethane appears brighter than the soft phase. The hard phase during phase separation formed island domain like phase. The results in all nanocomposites are similar, showing a distinct topology of phase separation of hard and soft segments (Fig 2b-f). Images of $\mathrm{Pu}$ phase structure and nanocomposites are similar to the images obtained by Zhang et al. [21].

The AFM images could be explained as follows: Glycerine reacted with MDI and then formed island domain like hard phase. This usually accompanied chemical reactions such as cross-link, so the segments shrank as a result [22] and formed caves like those in PU and nanocomposites.

The introduction of $0.5 \mathrm{wt} \%$ unmodified filler (Fig. 2c) makes the appearance of smaller islands, formed by hard phase, than in PU (Fig. 2b), visible in the pictures of cross-section surfaces of the nanocomposites. The use of $0.5 \mathrm{wt} . \%$ $\mathrm{SiO}_{2}$ modified by $\mathrm{NH}_{2}$ groups results in the growth of the size of islands formed by hard phase; moreover, they tend to merge into bigger agglomerates (Fig. 2d).

The size of the agglomerates of the hard domains was increased respectively to the nanofiller contents as shown in Fig. 2e and $\mathrm{fc}$.

Nanda and his co-workers have reported small amounts of POSS usually tending to combine with hard segments and affect the properties of the hard segments of PU [23]. Changes in the morphology of polyurethanes, caused by the introduction of POSS, were also observed by Zhang and co workers [24]. It can be assumed that the mechanisms of changes caused by the use of nanosilica are similar. Quantitative analysis of binary pictures was used for the description of morphology of PU hard phase and its nanocomposites. Since hard phase created islands, often merging into bigger agglomerates, the agglomerates' volume formed by hard phase was calculated and the results are presented in Fig. 3

The difference in the level of interaction by hydrogen bond between the hard segments of the materials can regarded as an explanation of the differences in the volume of the agglomerates created by hard phase of the examined materials; hence the determination of hydrogen bond index $(\mathrm{R})$ and phase separation index (DPS). The said difference in the level of interaction was determined basing on the vibrations of carbonyl groups occurring within the scope of wavenumbers $1760-1680 \mathrm{~cm}^{-1}$. The comparison of spectra in this scope for materials with equal nanosilica content modified with $\mathrm{NH}_{2}$ groups is shown in Fig. 4. 
a)

c)

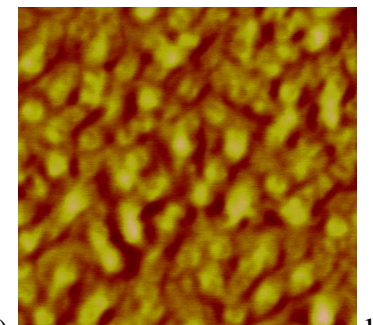

e) xprosont 1 b)

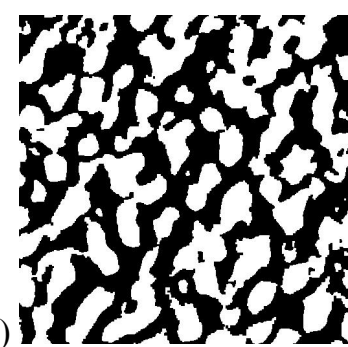

d)

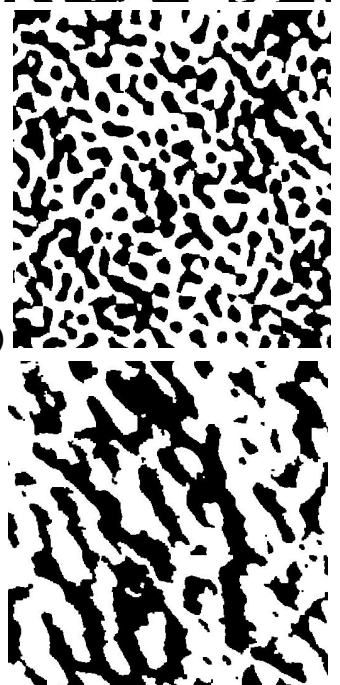

Figure 2: AFM phase images at $5 \mu \mathrm{m}$ scan sizes of (a) sample 0 and binary images: (b) sample 0 (c) sample 1 (d) sample 1A (e) sample 3 (f) sample $3 \mathrm{~A}$. $\mathrm{Z}$ ranges: $30^{\circ}$.

The $\mathrm{R}$ and DPS values of the polyurethane/nanosilica nanocomposites mixtures are given in Table 3. After the introduction of $0.5 \mathrm{wt} . \%$ of nanosilica, the $\mathrm{R}$ and DPS is higher than for polyurethane but modification causes a decrease in $\mathrm{R}$ and DPS. When a bigger amount of nanosilica is applied then $\mathrm{R}$ and DPS increase by adding $-\mathrm{NH}_{2}$ group on the surface of nanosilica.

Several factors influence the DPS of polyurethane such as molecular weight, segmental length, crystallizability of soft segments, overall composition and intra- and inter-segments interactions [25-27]. The addition $0.5 \mathrm{wt} \%$ nanosilica causes weakening of the hydrogen-bond interactions created between polyurethane hard segments; segmental incompatibility in the polyurethane decreases by adding nanosilicas (Table 3). This explains the formation of the structure visible in the cross-section of the materials (Fig 2c, d). After the introduction of a bigger amount of the filler we observe no weakening of hydrogen-bond interactions created between polyurethane hard segments. A bigger amount of the filler increases incompatibility in the polyurethanes, causing a higher degree of phase separation in the polyurethane (Table 3). 


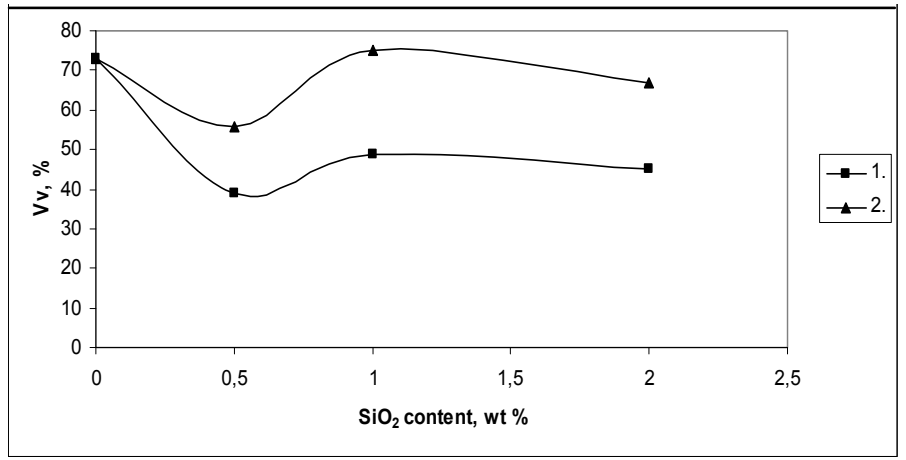

Figure 3: Influence of nanosilica content on volume fraction of hard domains agglomerates in PUR: (1) nanosilica, (2) modified nanosilica.

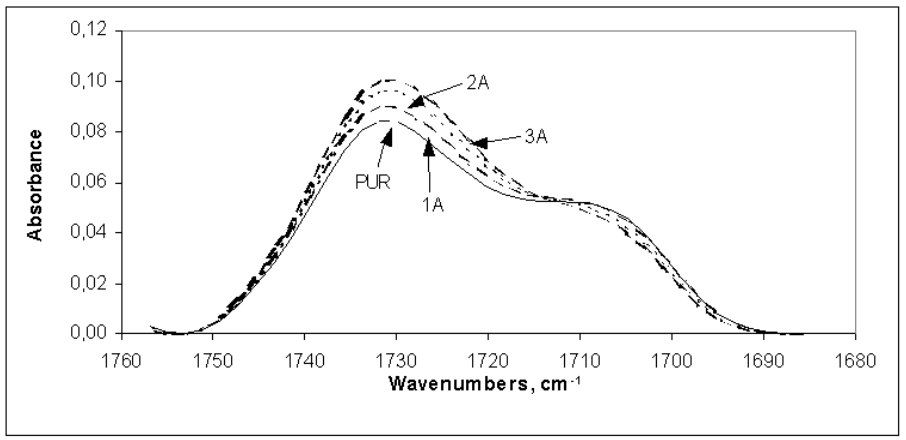

Figure 4: Influence of modified nanosilica content on FTIR spectrum in the range $1760-1680 \mathrm{~cm}^{-1}$.

Table 3: Parameters of polyurethane phase separations.

\begin{tabular}{|l|c|c|c|c|c|c|c|}
\hline Sample & 0 & 1 & 2 & 3 & $1 \mathrm{~A}$ & $2 \mathrm{~A}$ & $3 \mathrm{~A}$ \\
\hline R & 0.079 & 0.041 & 0.069 & 0.090 & 0.071 & 0.105 & 0.109 \\
\hline DPS & 0.073 & 0.040 & 0.064 & 0.082 & $0 ., 066$ & 0.095 & 0.099 \\
\hline
\end{tabular}

Moreover, in surface cross-sections of the examined nanocomposites bigger agglomerates of hard domains can be seen (Fig. 2e and f). Most probably, the increase in the degree of phase separation of this nanocomposites group can be attributed to the growth of the chain mobility in the polyurethane allowing the creation of more ordered phases, with respect to the polyurethane without nanosilica. A smaller amount of nanosilica weakened the interactions between hard segments but caused no growth of the chain mobility; it was only after adding bigger amounts of nanofiller (above 1\%) that an increase in nanocomposites chain mobility was observed. Surface modification of nanosilica by $\mathrm{NH}_{2}$ groups results in the increase in phase separation (Table 3), the volume 
of hard domain agglomerates increases (Fig. 2d and f), which is the result of reaction of $\mathrm{NH}_{2}$ groups on nanosilica surface and $\mathrm{NCO}$ groups in hard segments. This reaction weakens chain mobility and creates favourable conditions for phase separation in this nanocomposite group.

\section{Conclusion}

Within the framework of the work the influence of the quantity and modification of nanosilica on the properties of polyurethanes was assessed; the polyurethanes are intended to be used as short-term implants exposed to abrasion wear. The addition of $0.5 \mathrm{wt} \%$ of nanosilica caused a decrease in storage modulus and abrasion wear of nanocomposites. Bigger amounts of nanosilica result in a significant growth of storage modulus. The modification of nanosilica surface with $\mathrm{NH}_{2}$ groups adds to the increase in the modulus and to a favourable fall in the abrasion wear of the examined nanocomposites.

The joined qualitative and quantitative analysis of AFM pictures of polyurethane structure and its nanocomposites as well as the analysis of phase separation degree, performed on the basis of FTIR spectra, permitted to explain the causes of changes in the properties brought about by the introduction of nanofillers.

\section{Acknowledgements}

The authors are grateful to the Warsaw University of Technology for financial support of this study. Thanks are also offered to Dr Maria Zielecka from the Institute of Industrial Chemistry for the carrying out of nanosilica modifications.

\section{References}

[1] C. Hepburn: Polyurethane Elastomers, Elsev. Sci, Publ., London (1992).

[2] M. D. Lelah, S. L. Cooper. Polyurethanes in medicine, CRC Press, Boca Raton, 1986

[3] N.M.K. Lambda, K.A. Woodhouse, S.L. Cooper, Polyurethanes in Biomedical Applications, CRC Press, 1998

[4] Janik H., Postępy w badaniach struktur nadcząsteczkowych segmentowych poliuretanów, Polimery, 6, (2009), 419-500

[5] Janik H., Balas A., Budowa chemiczna i właściwości fizyczne usieciowanych poliuretanów segmentowych, Polimery, 3 (2009), 195201

[6] Ryszkowska J., Waśniewski B, Pytek A., Zielecka M; Kompozyty poliuretanowe $\mathrm{Z}$ nanokrzemionką modyfikowaną grupami izocyjanianowymi, Polimery, 10 (2009), 657-666

[7] Opera S.; Synthesis and properties of new polyurethane elastomers: influence of hard segment structure, Polimery, 2 (2010),111-117 
[8] B. Pourdeyhimi, Imaging and Image Analysis Applications for Plastics, Plastics Design Library, New York, 1999.

[9] J.C. Russ, R.T. Dehoff, Practical Stereology, Plenum Press, New York 1999.

[10] J. Ryszkowska, Quantitative image analysis of polyurethane/carbon nanotube composite microstructures, Materials Characterization, 60 (10), 2009, 1127-1132.

[11] Hafeman AE, Li B, Yoshii T, Zienkiewicz K, Davidson JM, Guelcher SA. Injectable biodegradable polyurethane scaffolds with release of platelet-derived growth factor for tissue repair and regeneration. Pharm Res 2008;25:2387-99

[12] Polish Committee for Standardization, Rubber-Determination of Abrasion Resistance Using a Rotating Cylindrical Drum Device, PNISO 4649; Warsaw, Poland, 1999.

[13] White, J. R.; De, S. K. Rubber Technologist's Handbook; Rapra Technology: Shrewsbury, England, 2001.

[14] Polish Committee for Standardization, Rubber, VulcanizedDetermination of Density, PN-ISO 27811AC1; Warsaw, Poland, 1996.

[15] Ryś J. Stereology of Materials. Kraków, Poland: Fotobit Design; 1995.

[16] Tien YI, Wei KH. Hydrogen bonding and mechanical properties in segmented montmorillonite/polyurethane nano composites of different hard segment ratios. Polymer 2001; 42:3213-21.

[17] Pretsch T, Jakob I, Müller W. Hydrolytic degradation and functional stability of a segmented shape memory poly(ester urethane). Polym Degrad Stabil , 2009;94:61-73.

[18] Gogotsi Y., Nanomaterials Handbook, CRC Taylor \&Francis, New York, 2006.

[19] Geceler K.E., Rosenberg E., Functional Nanomaterials, American Scientific Publishers, North Lewis Way Stevenson Ranch, 2006.

[20] Ajayan P.M., Schadler, Braun P.V. Nanocomposites Science and Technology, Wiley-VCH Verlag, Weinheim, 2003.

[21] S. Zhang R. Liu, J Jiang, C.heng Yang, M Chen, X.Ya Liu; Progress in Organic Coatings 70 (2011) 1-8

[22] Bliznyuk, V. N.; Tereshchenko, T. A.; Gumenna, M. A.; Tomza Y. P.; Shevchuk, A. V.; Klimenko, N. S.; Shevchenko, V. V. Polymer 2008, 49, 2298

[23] Nanda, A. K.; Wicks, D. A.; Madbouly, S. A.; Otaigbe, J. U. Macromolecules 2006, 39, 7037.

[24] Q. Zhang,H. He, K.ai Xi, X. Huang, X. Yu, X. Jia, Synthesis of NPhenylaminomethyl POSS and Its Utilization in Polyurethanes, Macromolecules, 2011, 44 (3), 550-557

[25] Oertel G. Polyurethane handbook. 2nd ed. New York: Hanser; 1993. 7 [Chapter 2].

[26] Nunes RCR, Fonseca JLC, Pereira MR. Polym Test 2000; 19:93-103.

[27] Nunes RCR, Pereira RA, Fonseca JLC, Pereira MR. Polym Test 2001; 20:707-12. 